\title{
Integrative network analysis identifies potential targets and drugs for ovarian cancer
}

Tianyu Zhang ${ }^{1,2}$, Liwei Zhang ${ }^{2}$ and Fuhai Li $i^{1,3^{*}}$

From The International Conference on Intelligent Biology and Medicine (ICIBM) 2019

Columbus, OH, USA. 9-11 June 2019

\begin{abstract}
Background: Though accounts for $2.5 \%$ of all cancers in female, the death rate of ovarian cancer is high, which is the fifth leading cause of cancer death (5\% of all cancer death) in female. The 5-year survival rate of ovarian cancer is less than $50 \%$. The oncogenic molecular signaling of ovarian cancer are complicated and remain unclear, and there is a lack of effective targeted therapies for ovarian cancer treatment.

Methods: In this study, we propose to investigate activated signaling pathways of individual ovarian cancer patients and sub-groups; and identify potential targets and drugs that are able to disrupt the activated signaling pathways. Specifically, we first identify the up-regulated genes of individual cancer patients using Markov chain Monte Carlo (MCMC), and then identify the potential activated transcription factors. After dividing ovarian cancer patients into several sub-groups sharing common transcription factors using K-modes method, we uncover the upstream signaling pathways of activated transcription factors in each sub-group. Finally, we mapped all FDA approved drugs targeting on the upstream signaling.

Results: The 427 ovarian cancer samples were divided into 3 sub-groups (with 100, 172, 155 samples respectively) based on the activated TFs (with 14, 25, 26 activated TFs respectively). Multiple up-stream signaling pathways, e.g., MYC, WNT, PDGFRA (RTK), PI3K, AKT TP53, and MTOR, are uncovered to activate the discovered TFs. In addition, 66 FDA approved drugs were identified targeting on the uncovered core signaling pathways. Forty-four drugs had been reported in ovarian cancer related reports. The signaling diversity and heterogeneity can be potential therapeutic targets for drug combination discovery.

Conclusions: The proposed integrative network analysis could uncover potential core signaling pathways, targets and drugs for ovarian cancer treatment.
\end{abstract}

Keywords: Ovarian cancer, Core signaling pathways, Network analysis, Drug discovery

\footnotetext{
* Correspondence: Fuhai.Li@wustl.edu

'Institute for Informatics (12), Washington University School of Medicine,

Washington University in St. Louis, St. Louis, MO 63130, USA

${ }^{3}$ Department of Pediatrics, Washington University School of Medicine,

Washington University in St. Louis, St. Louis, MO 63130, USA

Full list of author information is available at the end of the article
}

(C) The Author(s). 2020 Open Access This article is licensed under a Creative Commons Attribution 4.0 International License, which permits use, sharing, adaptation, distribution and reproduction in any medium or format, as long as you give appropriate credit to the original author(s) and the source, provide a link to the Creative Commons licence, and indicate if changes were made. The images or other third party material in this article are included in the article's Creative Commons licence, unless indicated otherwise in a credit line to the material. If material is not included in the article's Creative Commons licence and your intended use is not permitted by statutory regulation or exceeds the permitted use, you will need to obtain permission directly from the copyright holder. To view a copy of this licence, visit http://creativecommons.org/licenses/by/4.0/ The Creative Commons Public Domain Dedication waiver (http://creativecommons.org/publicdomain/zero/1.0/) applies to the data made available in this article, unless otherwise stated in a credit line to the data. 


\section{Background}

In United States, ovarian cancer is the fifth leading cause of cancer-related death in female [1], which accounts for $2.5 \%$ of all cancers in female, whereas, $5 \%$ of all cancer death in female [2]. In 2018, there are about 22,000 new cases of ovarian cancer, and 14,000 deaths [2]. The high death rate $(<50 \%$ of 5 year survival rate) is mainly because of the late diagnosis and aggressive high grade serous carcinoma [2, 3]. Platinum-based chemotherapy after surgical debulking is the standard treatment for ovarian cancer [4]. However, the cancer recurrence rate is high, and recurred tumors are often platinum resistant [4-6], with complicated mechanism of platinum resistance [7]. Though a few targeted therapies are being evaluated in clinical trials, e.g., VEGF, PARP, EGFR inhibitors [4], some of them are not very successful [4]. Therefore, novel targeted therapies and synergistic drug combinations are needed for ovarian cancer.

On the other hand, comprehensive multi-omics data of ovarian cancer patients have been profiled and analyzed [1, 8]. A set of genetic biomarkers, e.g., TP53, NOTCH, FOXM1, have been identified via association analyses [1]. Also, a few dysfunctional signaling pathways, e.g., MYC, TP53, PI3K/RAS, were be identified in ovarian cancer by mapping multi-omics data, e.g., differentially expressed genes, mutations, copy number variation, and methylation data, to the curated signaling pathways [8]. However, the functional consequence of these biomarkers and cross-talk of complicated signaling pathways in ovarian cancer remain unclear. It is still a challenge to discover effective drugs and synergistic drug combinations [9-12] for ovarian cancer based these valuable knowledge and multi-omics data.

In this study, we aim to systematically investigate potential activated core signaling pathways in ovarian cancer sub-groups by uncovering the up-stream signaling pathways of activated transcription factors (TFs), and identify all available FDA approved drugs targeting on these up-stream signaling and TFs. The combinations of these drugs have the potential to be synergy with standard platinum chemotherapy by disrupting multiple upstream signaling and their cross-talk. This study will provide a useful reference resource for repositioning effective drugs and drug combinations for ovarian cancer. The rest of the paper is organized as follows. The details of datasets and methods are provided in Section 2. The analysis results are presented in Section 3, followed by a summary in Section 4.

\section{Methods}

\section{Gene expression data of ovarian cancer and ovarian} normal tissue

We download the gene expression (RNAseq - RSEM expected_count (DESeq2 standardized)) data of 427 ovarian cancer samples (from The Cancer Genome Atlas (TCGA) [1]), and 88 ovarian normal samples (from Genotype-Tissue Expression (GTEx) [13]) from the Xena server [14].

\section{KEGG signaling pathways and regulatory network}

To obtain KEGG signaling pathways, the "Pathview" $R$ package [15] was employed to download KGMLs of signaling pathways. Then the "KEGGgraph" $\mathrm{R}$ package was used to extract nodes and edges of KEGG signaling pathways from KGMLs [16]. In total, 282 signaling pathways were collected from seven categories: metabolism, genetic information processing, environmental information processing, cellular processes, organismal systems, human diseases, and drug development. The TF-Target regulatory network was downloaded from the supplemental material of reference [17], which was derived from the TF binding site predictions for all target genes from TRANSFAC (v7.4) [18]. In summary, the TF-target regulatory network consists of 230 TFs, 12,733 target genes, and 79,100 TF-Target interactions.

\section{Drug combination screening data in NCI ALMANAC}

This dataset includes screening results of pairwise combinations of 104 FDA-approved anticancer drugs on NCI-60 cancer cell lines (59 cancer cell lines with detailed genomics profiles) [19]. Specifically, $~ 5232$ pairwise drug combinations were evaluated in each cancer cell line. Each drug combination was tested at either 9 or 15 dose points for a total of 2,809,671 dose-specific combinations. The detailed definition of synergistic drug combination score was introduced in reference [19].

\section{Selection of up-regulated genes for each sample}

In this study, the GTEx normal ovarian tissue samples were used as normal control versus ovarian cancer tumor samples from TCGA. The simple fold change and $p$-value $<=0.05$ (using $\mathrm{t}$ test) will result in too many upregulated genes. The Maximum Likelihood Estimate (MLE) method (see Fig. 1, red probability distribution function (PDF) curve) also generated too many upregulated genes. Thus, we employ the Markov chain Monte Carlo (MCMC) model to simulate the distribution of gene expression distribution of given genes based on the normal tissues. Let $\mathrm{x}, \mathrm{D}$ present the gene expression of a given gene and normal tissues respectively.

$$
\begin{aligned}
p(x \mid D) & =\frac{p(x D)}{p(D)}=\frac{\int_{\theta \in \Theta} p(x D \mid \theta) d \theta}{p(D)} \\
& =\frac{\int_{\theta \in \Theta} p(x \mid \theta) p(D \mid \theta)}{p(D)}
\end{aligned}
$$




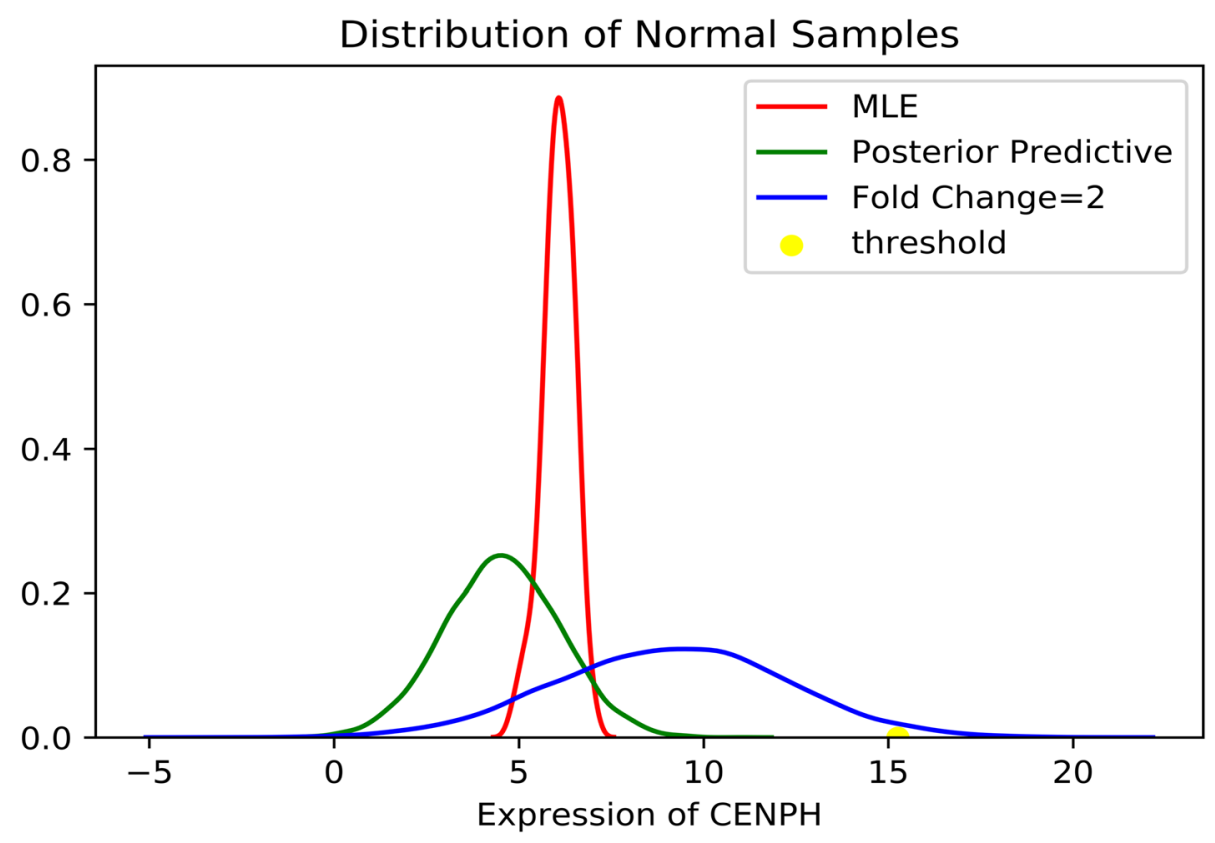

Fig. 1 Gene expression distribution of gene "CENPH"

$$
\begin{aligned}
\theta & =\left(\mu, \sigma^{2}\right), \Theta=\lfloor-\infty,+\infty\rfloor \times\lfloor 0,+\infty\rfloor, x: N \\
& =\left(\mu, \sigma^{2}\right) .
\end{aligned}
$$

We use the conjugate priors for $\mu$ and $\sigma^{2}$, which are the Normal distribution and Inverse Gamma distribution: $\mu: N\left(w_{0}, v_{0}\right), \sigma^{2}: I G\left(a_{0}, b_{0}\right)$.. To get uninformative priors, we set $w_{0}=0, v_{0}=+\infty, a_{0}=0, b_{0}=0$. Since it is hard to calculate eq. (1), we use MCMC method to simulate the distribution. The python package "Pymc3" [20] was employed to conduct the analysis. We set $w_{O}=$ $0, v_{O}=10^{4}, a_{O}=10^{-3}, b_{0}=10^{-3}$. The MCMC model is better than MLE (see the green PDF curve in Fig. 1), but still too many up-regulated genes will be selected. To further reduce the number of up-regulated genes, we empirically simulate the PDF of random variable $y=2 x$, and use the PDF of $y$ to calculate the $p$-value of given gene expression in ovarian cancer samples. Specifically, we selected up-regulated genes for each tumor sample with fold change $>=2$ and $p$-value $<=0.05$ (calculated based on the PDF of random variable y). We take the gene "CENPH" as an example to illustrate this analysis. The PDF generated by the MCMC model is more robust than generated by Maximum Likelihood Estimate (MLE) (see Fig. 1). The yellow point is the threshold and area under blue curve on the right of yellow point is about 0.05 (the calculation of $p$-value).

\section{Identification of activated TFs for individual ovarian cancer patients}

The Fisher's exact test (using hyper-geometric distribution) was used to identify the activated TFs by comparing the number of up-regulated targets vs. the number of all target genes, with the number of all the up-regulated genes vs. the number of all the genes tested. The $p$-value threshold, 0.05 , was used to select the activated TFs.

\section{Sub-grouping analysis using activated TFs}

We cluster 427 ovarian cancer samples using the identified activated TFs. We transform $p$-value to $0-1$ using 0.05 as a threshold. For categorical data, we use the k-modes method [21] for the sub-grouping analysis.

\section{Uncovering up-stream signaling of activated TFs}

All 282 signaling pathways from KEGG are investigated, and all the signaling cascades from the starting nodes to the activated TFs are extracted using the python package, NetworkX, to extract the up-stream signaling cascades starting from the beginning genes of individual signaling pathways to the given TFs. Then we score each signaling cascades using the average probability of genes (obtained from the MCMC analysis). To control the size of up-stream signaling network, the top 3 signaling cascades are kept.

\section{Target importance scoring}

The impact analysis (IA) evaluates both the topology and dynamics of a signaling pathway by considering the gene expression changes, the direction and type of signaling interaction, and the position and role of every gene in a pathway. A perturbation factor for each gene, 
$\operatorname{PF}\left(g_{i}\right)$, is calculated using the impact analysis method [22], as follows:

$$
P F\left(g_{i}\right)=\Delta E\left(g_{i}\right)+\sum_{j=1}^{n} \beta_{i j} \frac{P F\left(g_{j}\right)}{N_{d s}\left(g_{j}\right)},
$$

The term $\Delta \mathrm{E}\left(g_{i}\right)$ represents the signed normalized measured gene expression change of gene $\mathrm{g}_{i}$. The second term is the sum of perturbation factors of direct upstream genes of target gene $\mathrm{g}_{i}$, normalized by the number of downstream genes of each such gene $\mathrm{N}_{d s}\left(g_{j}\right)$. The value of $\beta_{i j}$ quantifies the strength of the interaction between genes $g_{j}$ and $g_{i}$. We use the probability density of gene expression instead of gene expression, which s will be more accurate considering that the standard deviation of different genes is different.

\section{Results}

Ovarian cancer samples were clustered into 3 groups based on activated TFs

Using the K-modes method, the 427 ovarian cancer samples were classified into 3 sub-groups (with 100, 172, 155 samples respectively) based on the activated TFs. For each sub-group, there is a center sample, and we use the center sample to characterize each sub-group. In another word, the activated TFs in the center sample were used as the activated TFs for this sub-group.

For visualization purpose, the principal component analysis (PCA) was employed to reduce the $230 \mathrm{TFs}$ to 2 dimensions (see Fig. 2). In one sub-group (Group 1), 14
TFs were activated: ELK1, FOXF2, NRF1, ETS2, NF.muE1, ADD1, TBP, SP1, GABP, E4F1, TELO2, MYC, YY1, NFE2L2A. Interestingly, these $14 \mathrm{TFs}$ are also activated in the other two groups. Group 2 and Group 3 have 26 and 25 TFs respectively. The additional TFs for Group2 are: AR, ETS1, GABPB1, GFI1, HMG, LHX3, NKX6.2, PAX3, PDX1, PITX2, REST(NRSF), S8. The additional TFs for Group 3 are: ARNT_MAX, ETS1, FOXN1, FOXO4, GABPB1, LHX3, NFATC2, NFIL3_ATF2, NKX6.2, PAX3, SREBF1.

\section{Up-stream signaling of activated TFs and related FDA approved drugs}

The up-stream signaling of activated TFs are shown in Figs. 3, 4 and 5. As can be seen, multiple important signaling pathways are uncovered, e.g., MYC, WNT, PDGF RA (RTK), PI3K, AKT TP53, and MTOR. This result is consistent with the discoveries in aforementioned references. There are 43 common genes among these 3 subgroups. We calculated and ranked the perturbation factor of 43 common genes. The top 5 related genes are TBP, MMP9, MYC, MAPK1, MTOR, which might play important roles in ovarian cancer. An interesting finding is MMP9, MYC, MAPK1, MTOR are all in Proteoglycans in cancer. Thus RTK-PI3K-AKT-MTOR can be an important signaling cascade for ovarian cancer. In addition, MTOR actives TP53 by cellular senescence pathway while T53 inhibits MTOR through IGF1/ MTOR. Since TP53 is the most frequently altered genes in ovarian cancer, the signaling loop between TP53 and MTOR might be a potential target of novel synergistic

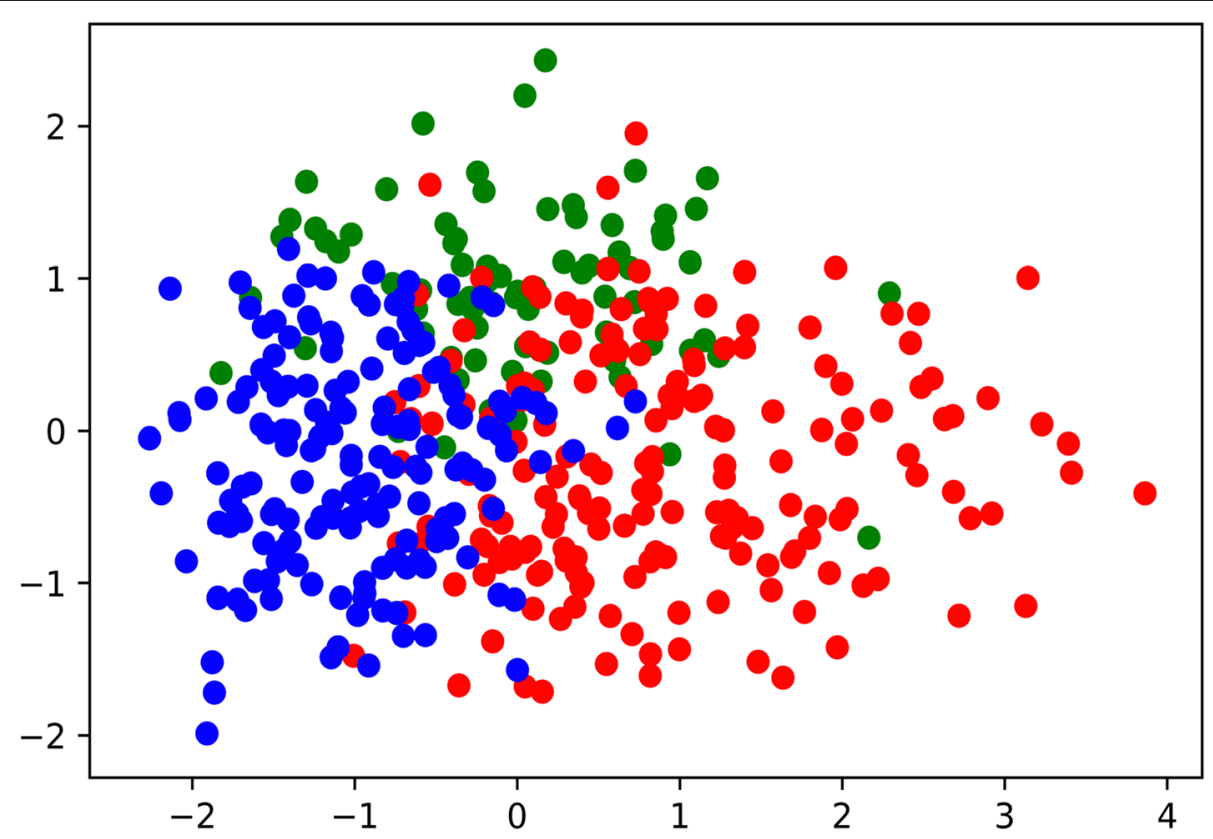

Fig. 2 Ovarian cancer samples are clustered into 3 groups based on the activated TFs 


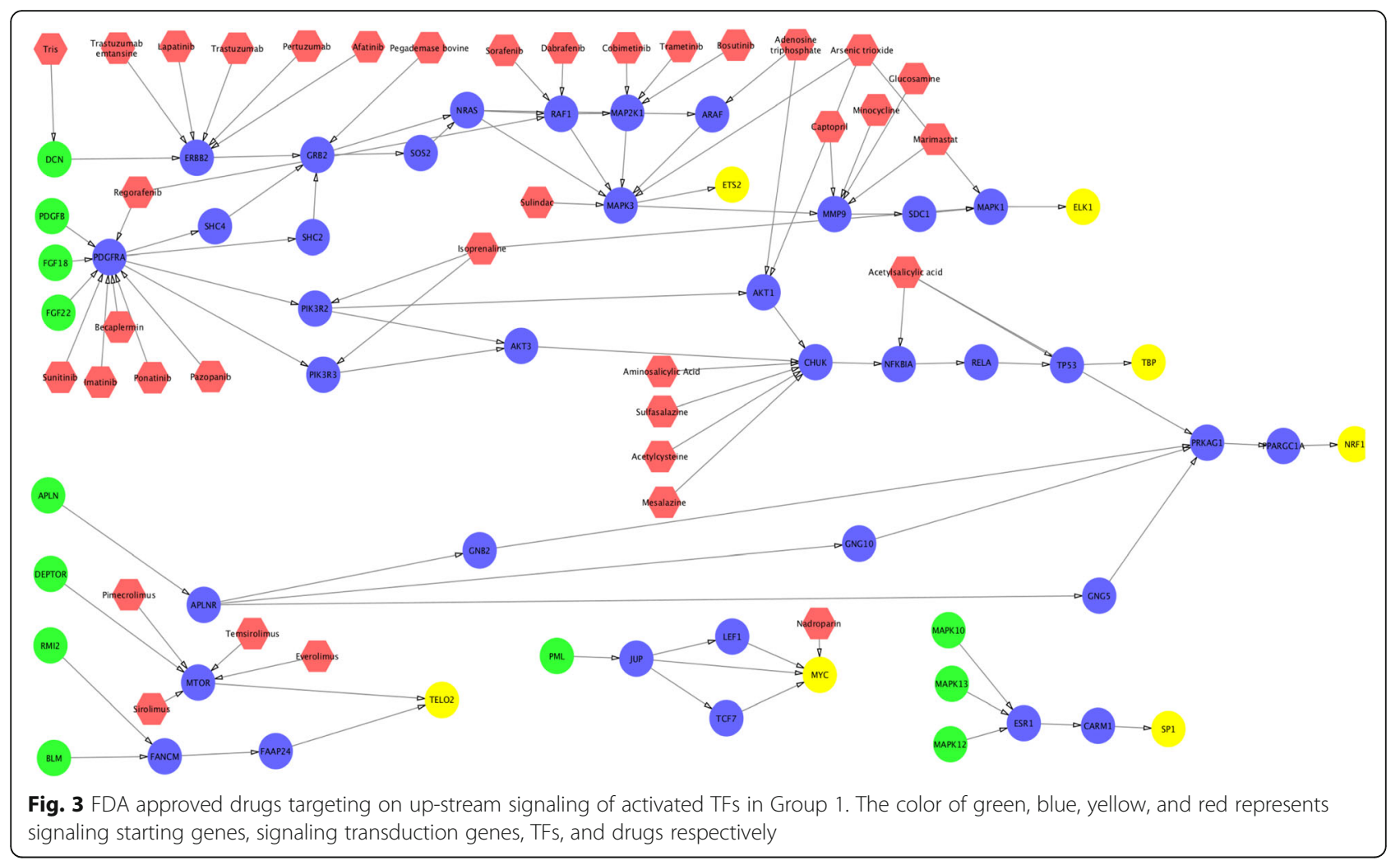

drug combinations. Moreover, drug combinations targeting on multiple up-stream signaling and TFs are also potentially synergy to disrupt the activated signaling of ovarian cancer sub-groups.

To investigate potential drugs that can potentially perturb these up-stream signaling networks, we mapped the FDA approved drugs on the signaling networks (see Figs. 3, 4 and 5). The target information was obtained from DrugBank (version 5.0.11) [23]. In total, 66 drugs (red nodes in Figs. 3, 4 and 5) were selected targeting on different targets. Through the literature search, 44 drugs had been reported to treat ovarian cancer (see Table 1).
In addition to these single drugs, we investigated effective combinations that appeared in our drug list, and validated in the drug combination screening on NCI 60 ovarian cancer cell lines (the synergy is defined with a threshold score higher than 8) (see Table 2). Moreover, we found that the top 10 drug targets of synergistic drug combinations are EGFR, TUBB1, TUBA4A, TUBB, TOP2B, MTOR, TUBB3, CYP19A1, ERS1 and BCL2. TUBB1, TUBA4A, TUBB, TUBB3 and TOP2B are related to cell proliferation. CYP19A1 and ERS1 are related to estrogen. BCL2 is the member of the Bcl-2 family of regulator proteins that regulate cell death.

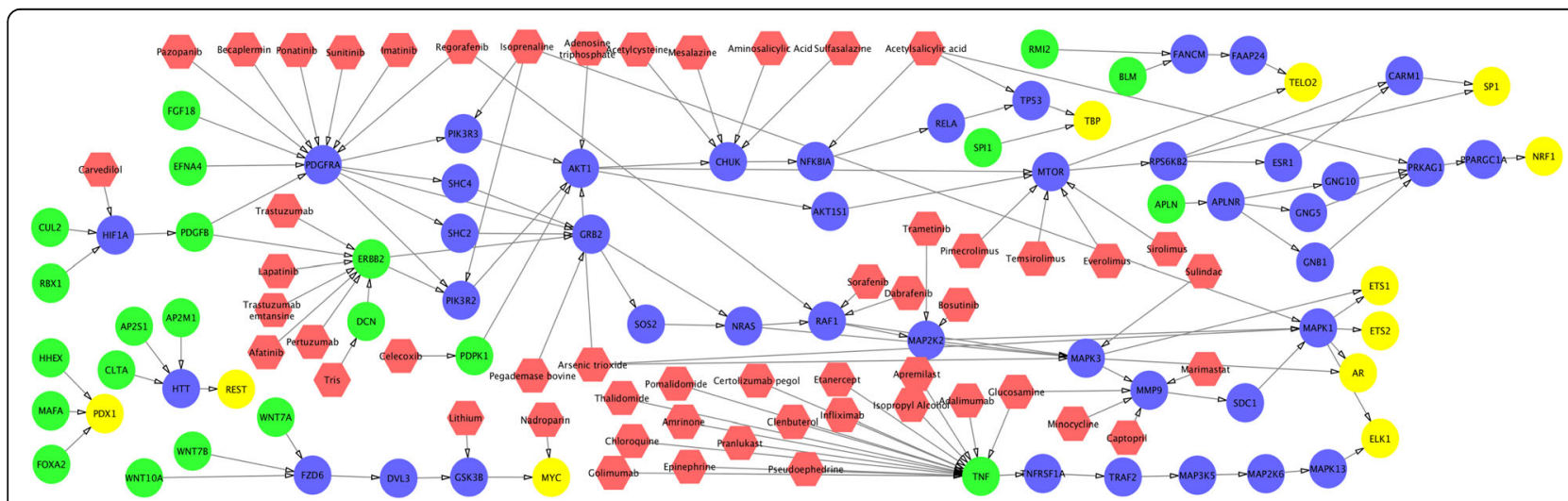

Fig. 4 FDA approved drugs targeting on up-stream signaling of activated TFs in group 2. The color of green, blue, yellow, and red represents signaling starting genes, signaling transduction genes, TFs, and drugs respectively 


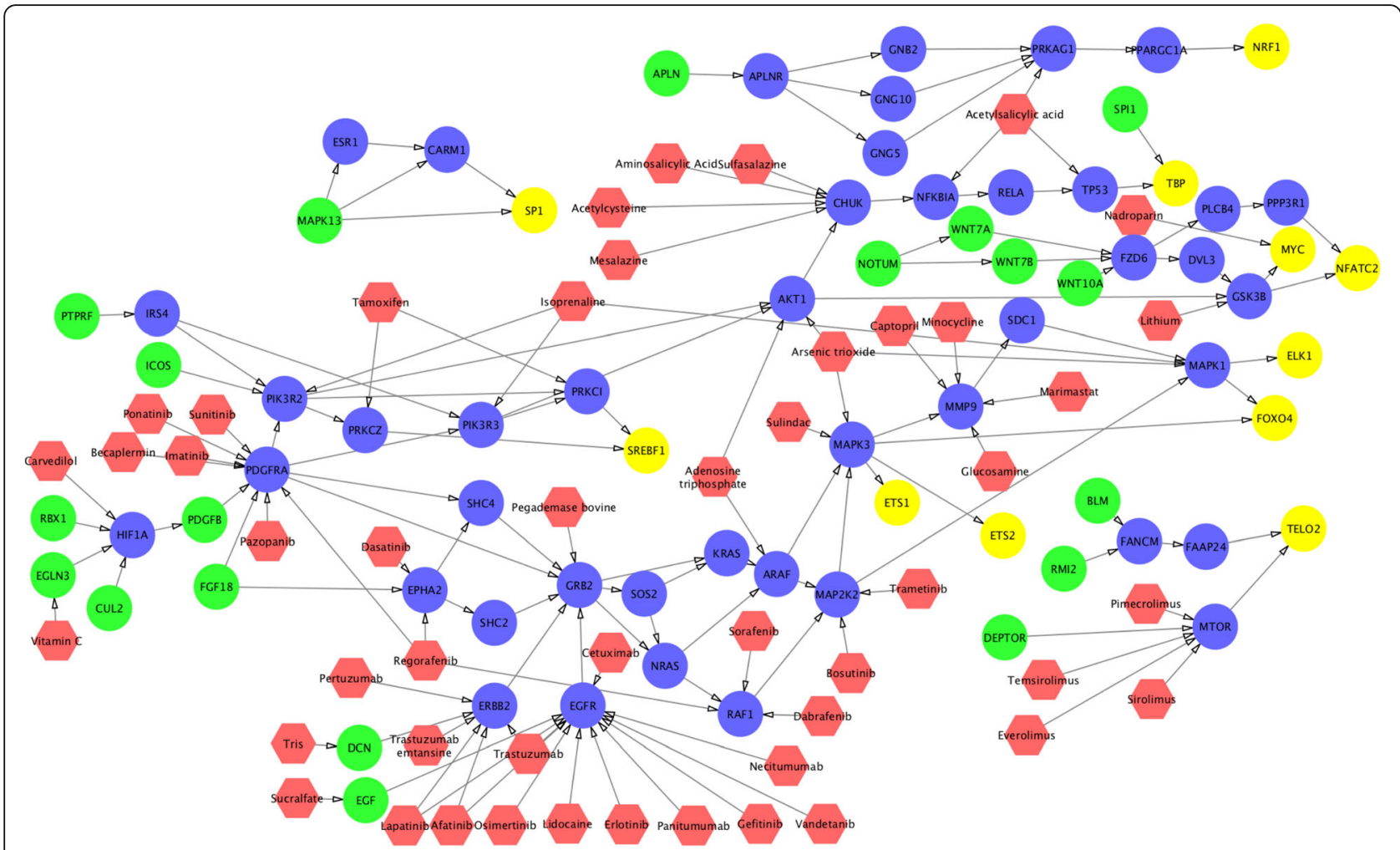

Fig. 5 FDA approved drugs targeting on up-stream signaling of activated TFs in group 3. The color of green, blue, yellow, and red represents signaling starting genes, signaling transduction genes, TFs, and drugs respectively

EGFR and MTOR are in PI3K-AKT pathway, and EGFR is one of the upstream of MTOR signaling. The combination of MTOR inhibitors, and EGFR, RTK, PI3K signaling inhibitors might be synergy to inhibit ovarian cancer development.

Moreover, we investigated the difference of activated core signaling pathways among these 3 sub-groups. The unique TFs appeared in the core signaling pathways in Group 2 and Group 3 are: PDX1, REST and AR; and ROXO4, SREB F1, NFATC2 respectively. In upstream signaling genes, PML, LEF1, MAPK12, FGF22, JUP, AKT3, MAPK10, MAP2K1, TCF7 are the unique genes for Group1. The CLTA, AR, RPS6KB2, AP2S1, AKT1S1, FOXA2, PDPK1, HTT, MAP2K6, TNFRSF1A, TNF, GNB1, MAFA, TRAF2, REST, HHEX, EFNA4, MAP3K5, PDX1 and AP2M1 are unique genes for Group2. The FOXO4, PLCB4, NFATC2, IRS4, KRAS, PRKCI, PTPRF, ICOS, EGLN3, NOTUM, PPP3R1, SREBF1, EPHA2, EGFR, EGF and PRKCZ are the unique genes for Group3. For Group 1, MAPK10, AKT3, FGF22 are in MAPK signaling pathway and RAS signaling pathway, and PML, JUP, LEF1, TCF7 are signaling cascades linking to MYC. For Group2, the signaling cascade from TNF to p38 is an upstream of p53. For Group3, many genes appeared in RAP1 signaling pathway. For the drugs listed in Table 1, for example, Celecoxib,
Chloroquine, Etanercept, Infliximab and Thalidomide targets on unique Group2 genes; and Cetuximab, Dasatinib, Erlotinib, Gefitinib, Lidocaine, Necitumumab, Osimertinib, Panitumumab, Sucralfate, Tamoxifen, Vandetanib, Vitamin $\mathrm{C}$ targets on Group 3 unique genes. The signaling diversity and heterogeneity can be potential therapeutic targets for drug combination discovery.

\section{Discussion}

Ovarian cancer is the fifth leading cause of cancerrelated death among women, and the 5-year survival rate is fewer than one half. Though a set of biomarkers and signaling pathways have been identified to be associated with ovarian cancer, the functional consequence of these biomarkers and signaling pathways remain unclear. Moreover, there is a lack of effective targeted therapies for ovarian cancer, especially for the platinum resistant ovarian cancer. In this study, we analyzed the gene expression data of ovarian cancer samples and ovarian normal tissues via network analysis. We aim to systematically explore the activated signaling pathways of individual ovarian cancer patients and sub-groups, and identify potential targets and drugs that are able to disrupt the core signaling pathways. There are still several limitations of the study. First, in addition to gene expression, mutation, methylation, and copy number 
Table 1 FDA approved drugs targeting on upstream signaling of activated transcription factors (TFs)

\begin{tabular}{|c|c|c|}
\hline Drug & Target & Titles of articles related to ovarian cancer treatment \\
\hline Acetylcysteine & CHUK & $\mathrm{N}$-acetylcysteine potentiates doxorubicin-induced ATM and p53 activation in ovarian cancer cells [24]. \\
\hline $\begin{array}{l}\text { Acetylsalicylic } \\
\text { acid }\end{array}$ & $\begin{array}{l}\text { TP53, PRKAG1, } \\
\text { NFKBIA }\end{array}$ & Aspirin inhibits growth of ovarian cancer by upregulating caspase-3 and downregulating bcl-2 [25]. \\
\hline Adalimumab & TNF & \\
\hline $\begin{array}{l}\text { Adenosine } \\
\text { triphosphate }\end{array}$ & ARAF, AKT1 & \\
\hline Afatinib & ERBB2, EGFR & $\begin{array}{l}\text { Afatinib reverses multidrug resistance in ovarian cancer via dually inhibiting ATP binding cassette subfamily B } \\
\text { member } 1 \text { [26]. }\end{array}$ \\
\hline $\begin{array}{l}\text { Aminosalicylic } \\
\text { acid }\end{array}$ & CHUK & \\
\hline Amrinone & TNF & \\
\hline Apremilast & TNF & \\
\hline Arsenic trioxide & $\begin{array}{l}\text { MAPK1, MAPK3, } \\
\text { AKT1 }\end{array}$ & Arsenic Trioxide inhibits the growth of human ovarian carcinoma cell line [27]. \\
\hline Becaplermin & PDGFRA & \\
\hline Bosutinib & $\begin{array}{l}\text { MAP2K1, } \\
\text { MAP2K2 }\end{array}$ & Ovarian Cancer Stem Cell Markers: Prognostic and Therapeutic Implications [28]. \\
\hline Captopril & MMP9 & $\begin{array}{l}\text { Epithelial ovarian cancer: A feasible plan for adjunctive treatment using simultaneous acyclovir, ambrisentan, } \\
\text { captopril, disulfiram, fluvoxamine-augmented ramelteon, icatibant, imiquimod peritoneal lavage, and plerixafor } \\
\text { [29]. }\end{array}$ \\
\hline Carvedilol & HIFA1 & Cardiovascular complications of antiangiogenic therapy in ovarian cancer patients [30]. \\
\hline Celecoxib & PDPK1 & $\begin{array}{l}\text { The effect of celecoxib on tumor growth in ovarian cancer cells and a genetically engineered mouse model of } \\
\text { serous ovarian cancer [31]. }\end{array}$ \\
\hline $\begin{array}{l}\text { Certolizumab } \\
\text { pegol }\end{array}$ & TNF & \\
\hline Cetuximab & EGFR & $\begin{array}{l}\text { Phase II Trial of Cetuximab and Carboplatin in Relapsed Platinum-Sensitive Ovarian Cancer and Evaluation of } \\
\text { Epidermal Growth Factor Receptor Expression: A Gynecologic Oncology Group Study [32]. }\end{array}$ \\
\hline Chloroquine & TNF & $\begin{array}{l}\text { Low concentration of chloroquine enhanced efficacy of cisplatin in the treatment of human ovarian cancer } \\
\text { dependent on autophagy [33]. }\end{array}$ \\
\hline Clenbuterol & TNF & \\
\hline Cobimetinib & MAP2K1 & \\
\hline Dabrafenib & RAF1 & \\
\hline Dasatinib & EPHA2 & Activity of the multikinase inhibitor dasatinib against ovarian cancer cells [34]. \\
\hline Epinephrine & TNF & \\
\hline Erlotinib & EGFR & $\begin{array}{l}\text { Erlotinib or gefitinib for the treatment of relapsed platinum pretreated non-small cell lung cancer and ovarian } \\
\text { cancer: a systematic review [35]. }\end{array}$ \\
\hline Etanercept & TNF & Study of etanercept, a tumor necrosis factor-alpha inhibitor, in recurrent ovarian cancer [36]. \\
\hline Everolimus & MTOR & Effective use of everolimus as salvage chemotherapy for ovarian clear cell carcinoma: a case report [37]. \\
\hline Gefitinib & EGFR & Gefitinib (ZD1839) increases the efficacy of cisplatin in ovarian cancer cells [38]. \\
\hline Glucosamine & TNF, MMP9 & \\
\hline Golimumab & TNF & \\
\hline Imatinib & PDGFRA & $\begin{array}{l}\text { Imatinib mesylate (Gleevec) inhibits ovarian cancer cell growth through a mechanism dependent on platelet- } \\
\text { derived growth factor receptor alpha and Akt inactivation [39]. }\end{array}$ \\
\hline Infliximab & TNF & $\begin{array}{l}\text { Infliximab, a humanised anti-TNF-a monoclonal antibody, exhibits biological activity in the ovarian tumor } \\
\text { microenvironment in patients [40]. }\end{array}$ \\
\hline Isoprenaline & $\begin{array}{l}\text { PIK3R3, PIK3R2, } \\
\text { MAPK1 }\end{array}$ & Targeted anti-vascular therapies for ovarian cancer: current evidence [41]. \\
\hline Isopropyl alcohol & TNF & \\
\hline Lapatinib & ERBB2, EGFR & $\begin{array}{l}\text { A phase II evaluation of lapatinib in the treatment of persistent or recurrent epithelial ovarian or primary } \\
\text { peritoneal carcinoma: a gynecologic oncology group study [32]. }\end{array}$ \\
\hline
\end{tabular}


Table 1 FDA approved drugs targeting on upstream signaling of activated transcription factors (TFs) (Continued)

\begin{tabular}{|c|c|c|}
\hline Drug & Target & Titles of articles related to ovarian cancer treatment \\
\hline Lidocaine & EGFR & Lidocaine inhibits the invasion and migration of TRPV6-expressing cancer cells by TRPV6 downregulation [42]. \\
\hline Lithium & GSK3B & Lithium and inhibition of GSK3 $\beta$ as a potential therapy for serous ovarian cancer [43]. \\
\hline Marimastat & MMP9 & Marimastat (BB2516): Current status of development [44]. \\
\hline Mesalazine & CHUK & \\
\hline Minocycline & MMP9 & Minocycline inhibits malignant ascites of ovarian cancer through targeting multiple signaling pathways [45]. \\
\hline Nadroparin & MYC & \\
\hline Necitumumab & EGFR & \\
\hline Osimertinib & EGFR & \\
\hline Panitumumab & EGFR & $\begin{array}{l}\text { Targeting the Epidermal Growth Factor Receptor in Epithelial Ovarian Cancer: Current Knowledge and Future } \\
\text { Challenges [46]. }\end{array}$ \\
\hline Pazopanib & PDGFRA & Incorporation of Pazopanib in Maintenance Therapy of Ovarian Cancer [47]. \\
\hline $\begin{array}{l}\text { Pegademase } \\
\text { bovine }\end{array}$ & GRB2 & \\
\hline Pertuzumab & ERBB2 & $\begin{array}{l}\text { A randomized phase II study evaluating the combination of carboplatin-based chemotherapy with pertuzu- } \\
\text { mab versus carboplatin-based therapy alone in patients with relapsed, platinum-sensitive ovarian cancer [48]. }\end{array}$ \\
\hline Pimecrolimus & MTOR & $\begin{array}{l}\text { Topical pimecrolimus inhibits high-dose UVB irradiation-induced epidermal Langerhans cell migration, via } \\
\text { regulation of TNF-a and E-cadherin [49]. }\end{array}$ \\
\hline Pomalidomide & TNF & \\
\hline Ponatinib & PDGFRA & $\begin{array}{l}\text { Ponatinib Shows Potent Antitumor Activity in Small Cell Carcinoma of the Ovary Hypercalcemic Type } \\
(\mathrm{SCCOHT}) \text { through Multikinase Inhibition [50]. }\end{array}$ \\
\hline Pranlukast & TNF & \\
\hline Pseudoephedrine & TNF & \\
\hline Regorafenib & $\begin{array}{l}\text { EPHA2, RAF1, } \\
\text { PDGFRA }\end{array}$ & $\begin{array}{l}\text { 301P Interim Analysis of A Single-Arm Phase } 2 \text { Clinical Trial of Regorafenib in Patients with Epithelial Ovarian } \\
\text { Cancer [51]. }\end{array}$ \\
\hline Sirolimus & MTOR & $\begin{array}{l}\text { Rapamycin by itself and additively in combination with carboplatin inhibits the growth of ovarian cancer cells } \\
\text { [52]. }\end{array}$ \\
\hline Sorafenib & RAF1 & $\begin{array}{l}\text { Activity of sorafenib in recurrent ovarian cancer and primary peritoneal carcinomatosis: a gynecologic } \\
\text { oncology group trial [53]. }\end{array}$ \\
\hline Sucralfate & EGF & \\
\hline Sulfasalazine & CHUK & Sulfasalazine Inhibits IL-2 Expression in Ovarian Cancer Cells [54]. \\
\hline Sulindac & MAKP3 & $\begin{array}{l}\text { The conventional nonsteroidal anti-inflammatory drug sulindac sulfide arrests ovarian cancer cell growth via } \\
\text { the expression of NAG-1/MIC-1/GDF-15 [55]. }\end{array}$ \\
\hline Sunitinib & PDGFRA & Autophagy Inhibition Enhances Sunitinib Efficacy in Clear Cell Ovarian Carcinoma [56]. \\
\hline Tamoxifen & $\begin{array}{l}\text { PRKCZ, ESR1, } \\
\text { PRKCl }\end{array}$ & The efficacy of tamoxifen in patients with advanced epithelial ovarian cancer [57]. \\
\hline Temsirolimus & MTOR & $\begin{array}{l}\text { Temsirolimus in women with platinum-refractory/resistant ovarian cancer or advanced/recurrent endometrial } \\
\text { carcinoma. A phase II study of the AGO-study group (AGO-GYN8) [58]. }\end{array}$ \\
\hline Thalidomide & TNF & Thalidomide and lenalidomide for recurrent ovarian cancer: A systematic review of the literature [59]. \\
\hline Trametinib & $\begin{array}{l}\text { MAP2K1, } \\
\text { MAP2K2 }\end{array}$ & $\begin{array}{l}\text { The mTORC1/2 Inhibitor AZD8055 Strengthens the Efficiency of the MEK Inhibitor Trametinib to Reduce the } \\
\text { Mcl-1/[Bim and Puma] ratio and to Sensitize Ovarian Carcinoma Cells to ABT-737 [60]. }\end{array}$ \\
\hline Trastuzumab & ERBB2, EGFR & Trastuzumab Sensitizes Ovarian Cancer Cells to EGFR-targeted Therapeutics [61]. \\
\hline $\begin{array}{l}\text { Trastuzumab } \\
\text { emtansine }\end{array}$ & ERBB2 & $\begin{array}{l}\text { Superior in vitro and in vivo activity of trastuzumab-emtansine (T-DM1) in comparison to trastuzumab, pertuzu- } \\
\text { mab and their combination in epithelial ovarian carcinoma with high HER2/neu expression [62]. }\end{array}$ \\
\hline Tris & DCN & $\begin{array}{l}\text { Synergism from Combinations of tris(benzimidazole) monochloroplatinum(II) Chloride with Capsaicin, } \\
\text { Quercetin, Curcumin and Cisplatin in Human Ovarian Cancer Cell Lines [63]. }\end{array}$ \\
\hline Vandetanib & EGFR & $\begin{array}{l}\text { Vandetanib, designed to inhibit VEGFR2 and EGFR signaling, had no clinical activity as monotherapy for } \\
\text { recurrent ovarian cancer and no detectable modulation of VEGFR2 [64]. }\end{array}$ \\
\hline Vitamin c & EGLN3 & The Effect of Intravenous Vitamin C on Cancer- and Chemotherapy-Related Fatigue and Quality of Life [65]. \\
\hline
\end{tabular}


Table 2 Validated synergistic drug combinations in NCl-60

\begin{tabular}{|c|c|c|c|c|c|}
\hline Drug 1 & Drug 2 & Target 1 & Target 2 & Score & Cell line \\
\hline Erlotinib & Dasatinib & EGFR & EPHA2 & 34.44 & IGROV1 \\
\hline Gefitinib & Dasatinib & EGFR & EPHA2 & 23.22 & IGROV1 \\
\hline Vandetanib & Dasatinib & EGFR & EPHA2 & 18.44 & IGROV1 \\
\hline Dasatinib & Tamoxifen & EPHA2 & PRKCZ, PRKCI & 16.78 & IGROV1 \\
\hline Lapatinib & Sirolimus & ERBB2, EGFR & MTOR & 14.00 & IGROV1 \\
\hline Vandetanib & Everolimus & EGFR & MTOR & 13.56 & IGROV1 \\
\hline elecoxib & Dasatinib & PDPK1 & EPHA2 & 13.11 & IGROV1 \\
\hline Lapatinib & Everolimus & ERBB2, EGFR & MTOR & 12.44 & IGROV1 \\
\hline rolimus & Tamoxifen & MTOR & PRKCZ, PRKCI & 11.67 & IGROV1 \\
\hline Lapatinib & Dasatinib & ERBB2, EGFR & EPHA2 & 11.00 & IGROV1 \\
\hline efitinib & Everolimus & EGFR & MTOR & 10.78 & IGROV1 \\
\hline Dasatinib & Imatinib & EPHA2 & PDGFRA & 10.56 & IGROV1 \\
\hline Celecoxib & Vandetanib & PDPK1 & EGFR & 9.11 & IGROV1 \\
\hline rolimus & Vandetanib & MTOR & EGFR & 8.78 & IGROV1 \\
\hline Erlotinib & Tamoxifen & EGFR & PRKCZ, PRKCI & 8.33 & IGROV1 \\
\hline Dasatinib & Tamoxifen & EPHA2 & PRKCZ, PRKCI & 11.33 & OVCAR-3 \\
\hline Sirolimus & Everolimus & MTOR & MTOR & 9.56 & OVCAR-3 \\
\hline elecoxib & Dasatinib & PDPK1 & EPHA2 & 9.44 & OVCAR-3 \\
\hline Thalidomide & Dasatinib & TNF & EPHA2 & 8.89 & OVCAR-3 \\
\hline irolimus & Gefitinib & MTOR & EGFR & 10.56 & OVCAR-4 \\
\hline Gefitinib & Everolimus & EGFR & MTOR & 9.44 & OVCAR-4 \\
\hline Lapatinib & Sirolimus & ERBB2, EGFR & MTOR & 9.44 & OVCAR-4 \\
\hline Vandetanib & Tamoxifen & EGFR & PRKCZ, PRKCI & 9.33 & OVCAR-5 \\
\hline Dasatinib & Tamoxifen & EPHA2 & PRKCZ, PRKCI & 14.78 & SK-OV-3 \\
\hline verolimus & Tamoxifen & MTOR & PRKCZ, PRKCI & 11.78 & SK-OV-3 \\
\hline Lapatinib & Dasatinib & ERBB2, EGFR & EPHA2 & 10.11 & SK-OV-3 \\
\hline Celecoxib & Dasatinib & PDPK1 & EPHA2 & 9.56 & SK-OV-3 \\
\hline Gefitinib & Dasatinib & EGFR & EPHA2 & 9.11 & SK-OV-3 \\
\hline
\end{tabular}

variation data should be integrated in the network analysis to uncover the TFs, and up-stream signaling. Second, the signaling cross-talk among these up-streams are not investigated, which might be responsible for drug resistance. In the future, we will also investigate the signaling network and TFs of platinum resistant ovarian cancer samples; and conduct the network-based drug repositioning approaches $[66,67]$ to reposition drugs $[68$, 69] and drug combinations [70] for ovarian cancer treatment.

\section{Conclusions}

The purpose of this study is to systematically uncover potential activated core signaling pathways in ovarian cancer using integrative network analysis. We identified about 37 activated TFs from three sub-groups of ovarian cancer, as well as a set of up-stream signaling pathways linking to these TFs, e.g., WNT, TP53, MYC, AKT, RAS,
mTOR, PDGFRA signaling pathways. In addition, 66 FDA approved drugs were identified targeting on the uncovered core signaling pathways. Forty-four drugs had been reported in ovarian cancer related reports. Combinations of these drugs could be potentially synergy to disrupt the cross-talk of multiple activated signaling pathways and TFs for better ovarian therapy. These uncovered signaling networks, TFs and drugs can be used as reference resources to support biomedical studies in ovarian cancer.

\section{Abbreviations}

TCGA: The cancer genome atlas; GTEx: Genotype-tissue expression; KEGG: Kyoto encyclopedia of genes and genomes; TF: Transcription factor; MCMC: Markov chain Monte Carlo; ALMANAC: A large matrix of antineoplastic agent combinations

\section{Acknowledgements}

We would like to thank colleagues in Institute for Informatics (I2) for the helpful discussions.

\section{About this supplement}

This article has been published as part of BMC Medical Genomics Volume 13 Supplement 9, 2020: The International Conference on Intelligent Biology and Medicine (ICIBM) 2019: Computational methods and application in medical genomics (part 2). The full contents of the supplement are available online at https://bmcmedgenomics.biomedcentral.com/articles/supplements/ volume-13-supplement-9.

\section{Authors' contributions}

FL conceived the project. Methodology was designed by TY, LZ, FL. TY performed the data analysis. The original draft was written by TZ and FL. All authors have read and approved the manuscript.

\section{Funding}

Publication costs are funded by the startup funding from Institute for Informatics (I2) and Department of Pediatrics, to Dr. Fuhai Li.

\section{Availability of data and materials}

Gene expression data is available at:

https://xenabrowser.net/datapages/?dataset=TCGA-GTEx-TARGET-gene-expcounts.deseq2-normalized.log2\&host=https\%3A\%2F\%2Ftoil.xenahubs.net).

The TF-Target interactions, derived from TRANSFAC database, are third party data and are available at: https://genome.cshlp.org/content/24/11/1869/ suppl/DC1

$\mathrm{NCl}-60$ Drug combination screening data is available at: https://dtp.cancer.gov/discovery_development/nci-60/ Drug-Target interactions are derived from DrugBank:

https://www.drugbank.ca/releases/latest

\section{Ethics approval and consent to participate}

Not applicable.

\section{Consent for publication}

Not applicable.

\section{Competing interests}

The authors declare that they have no competing interests.

\section{Author details}

${ }^{1}$ Institute for Informatics (12), Washington University School of Medicine, Washington University in St. Louis, St. Louis, MO 63130, USA. ${ }^{2}$ Dalian University of Technology, Dalian 116024, China. ${ }^{3}$ Department of Pediatrics, Washington University School of Medicine, Washington University in St. Louis, St. Louis, MO 63130, USA. 


\section{Published: 21 September 2020}

\section{References}

1. Network TCGAR, Bell D, Berchuck A, Birrer M, Chien J, Cramer DW, et al. Integrated genomic analyses of ovarian carcinoma. Nature 2011;474:609. https://doi.org/10.1038/nature10166

2. Torre LA, Trabert B, DeSantis CE, Miller KD, Samimi G, Runowicz CD, et al. Ovarian cancer statistics, 2018. CA Cancer J Clin. 2018;68:284-96. https://doi. org/10.3322/caac.21456.

3. Hoppenot C, Eckert MA, Tienda SM, Lengyel E. Who are the long-term survivors of high grade serous ovarian cancer? Gynecol Oncol. 2018;148: 204-12. https://doi.org/10.1016/j.ygyno.2017.10.032.

4. Cortez AJ, Tudrej P, Kujawa KA, Lisowska KM. Advances in ovarian cancer therapy. Cancer Chemother Pharmacol. 2018;81:17-38. https://doi.org/10. 1007/s00280-017-3501-8.

5. Dasari S, Tchounwou PB. Cisplatin in cancer therapy: molecular mechanisms of action. Eur J Pharmacol. 2014;740:364-78. https://doi.org/10.1016/j.ejphar. 2014.07.025

6. Zhang T, Xu J, Deng S, Zhou F, Li J, Zhang L, et al. Core signaling pathways in ovarian cancer stem cell revealed by integrative analysis of multi-marker genomics data. PLoS One. 2018;13:e0196351

7. Binju M, Padilla MA, Singomat T, Kaur P, Suryo Rahmanto Y, Cohen PA, et al. Mechanisms underlying acquired platinum resistance in high grade serous ovarian cancer - a mini review. Biochim Biophys Acta - Gen Subj 2019;1863: 371-378. doi:https://doi.org/10.1016/j.bbagen.2018.11.005.

8. Sanchez-Vega F, Mina M, Armenia J, Chatila WK, Luna A, La KC, et al. Oncogenic signaling pathways in the cancer genome atlas. Cell. 2018;173: 321-337.e10. doi:https://doi.org/10.1016/j.cell.2018.03.035.

9. Wu H, Miller E, Wijegunawardana D, Regan K, Payne PRO, Li F. MD-Miner: a network-based approach for personalized drug repositioning. BMC Syst Biol. 2017;11.

10. Regan KE, Payne PRO, Li F. Integrative network and transcriptomics-based approach predicts genotype- specific drug combinations for melanoma. AMIA Jt Summits Transl Sci proceedings AMIA Jt Summits Transl Sci. 2017; 2017:247-56.

11. Regan-Fendt KE, Xu J, DiVincenzo M, Duggan MC, Shakya R, Na R, et al. Synergy from gene expression and network mining (SynGeNet) method predicts synergistic drug combinations for diverse melanoma genomic subtypes. npj Syst Biol Appl. 2019;5(6).

12. Xu J, Regan-Fendt K, Deng S, Carson WE, Payne PRO, Li F. Diffusion mapping of drug targets on disease signaling network elements reveals drug combination strategies. In: Pacific Symposium on Biocomputing, 2018. 2018

13. Lonsdale J, Thomas J, Salvatore M, Phillips R, Lo E, Shad S, et al. The genotype-tissue expression (GTEx) project. Nat Genet 2013;45:580. https:// doi.org/10.1038/ng.2653.

14. Xena Server URL: https://xenabrowser.net/datapages/?dataset=TCGA-GTEX TARGET-gene-exp-counts.deseq2-normalized.log2\&host=https\%3A\%2F\%2 Ftoil.xenahubs.net

15. Luo W, Brouwer C. Pathview: An R/Bioconductor package for pathwaybased data integration and visualization. Bioinformatics. 2013;29(14):183031. https://doi.org/10.1093/bioinformatics/btt285.

16. Zhang JD, Wiemann S. KEGGgraph: A graph approach to KEGG PATHWAY in R and bioconductor. Bioinformatics. 2009;25(11):1470-71. https://doi.org/10. 1093/bioinformatics/btp167.

17. Osmanbeyoglu HU, Pelossof R, Bromberg JF, Leslie CS. Linking signaling pathways to transcriptional programs in breast cancer. Genome Res. 2014; 24:1869-80. https://doi.org/10.1101/gr.173039.114.

18. Liberzon A, Subramanian A, Pinchback R, Thorvaldsdóttir $H$, Tamayo $P$, Mesirov JP. Molecular signatures database (MSigDB) 3.0. Bioinformatics. 2011:27:1739-40

19. Holbeck SL, Camalier R, Crowell JA, Govindharajulu JP, Hollingshead M, Anderson LW, et al. The National Cancer Institute ALMANAC: a comprehensive screening resource for the detection of anticancer drug pairs with enhanced therapeutic activity. Cancer Res. 2017;77:3564-76.

20. Salvatier J, Wiecki TV, Fonnesbeck C. Probabilistic programming in Python using PyMC3. PeerJ Comput Sci. 2016;2:e55. https://doi.org/10.7717/peerj-cs.55.

21. Huang Z. Extensions to the k-means algorithm for clustering large data sets with categorical values. Data Min Knowl Discov. 1998;2:283-304. https://doi. org/10.1023/A:1009769707641.
22. Tarca AL, Draghici S, Khatri P, Hassan SS, Mittal P, Kim J-S, et al. A novel signaling pathway impact analysis. Bioinformatics. 2009;25:75-82. https://doi. org/10.1093/bioinformatics/btn577.

23. Wishart DS, Feunang YD, Guo AC, Lo EJ, Marcu A, Grant JR, et al. DrugBank 5.0: a major update to the DrugBank database for 2018. Nucleic Acids Res. 2018:46:D1074-82

24. Brum G, Carbone T, Still E, Correia V, Szulak K, Calianese D, et al. Nacetylcysteine potentiates doxorubicin-induced ATM and p53 activation in ovarian cancer cells. Int J Oncol. 2012;42:211-8. https://doi.org/10.3892/ijo. 2012.1680 .

25. Li L, Mao X, Qin X, Zhou M, Xing H, Dong F, et al. Aspirin inhibits growth of ovarian cancer by upregulating caspase-3 and downregulating bcl-2. Oncol Lett. 2016;12:93-6. https://doi.org/10.3892/ol.2016.4607.

26. Wang S, Liu S, Zhao B, Yang F, Wang Y, Liang Q-Y, et al. Afatinib reverses multidrug resistance in ovarian cancer via dually inhibiting ATP binding cassette subfamily B member 1. Oncotarget. 2015;6:26142-60. https://doi. org/10.18632/oncotarget.4536.

27. Bornstein J, Sagi S, Haj A, Harroch J, Fares F. Arsenic trioxide inhibits the growth of human ovarian carcinoma cell line. Gynecol Oncol 2005;99:726729. doi:https://doi.org/10.1016/j.ygyno.2005.07.125.

28. Burgos-Ojeda D, Rueda BR, Buckanovich RJ. Ovarian cancer stem cell markers: prognostic and therapeutic implications. Cancer Lett. 2012;322:1-7. https://doi.org/10.1016/j.canlet.2012.02.002.

29. Kast RE. Epithelial ovarian cancer: a feasible plan for adjunctive treatment using simultaneous acyclovir, ambrisentan, captopril, disulfiram, fluvoxamine-augmented ramelteon, icatibant, imiquimod peritoneal lavage, and plerixafor. J Cancer Ther Res. 2012;1. https://doi.org/10.7243/2049-7962$1-2$

30. Chang H-M, Moudgil R, Scarabelli T, Okwuosa TM, Yeh ETH. Cardiovascular complications of Cancer therapy: best practices in diagnosis, prevention, and management: part 1. J Am Coll Cardiol. 2017;70:2536-51. https://doi. org/10.1016/j.jacc.2017.09.1096.

31. Suri A, Sheng $X$, Schuler KM, Zhong $Y$, Han X, Jones HM, et al. The effect of celecoxib on tumor growth in ovarian cancer cells and a genetically engineered mouse model of serous ovarian cancer. Oncotarget. 2016;7: 39582-94. https://doi.org/10.18632/oncotarget.8659.

32. Secord AA, Blessing JA, Armstrong DK, Rodgers WH, Miner Z, Barnes MN, et al. Phase II trial of cetuximab and carboplatin in relapsed platinumsensitive ovarian cancer and evaluation of epidermal growth factor receptor expression: a gynecologic oncology group study. Gynecol Oncol. 2008;108: 493-9. https://doi.org/10.1016/j.ygyno.2007.11.029.

33. Zhu J, Zheng $Y$, Zhang $H$, Zhu J, Sun H. Low concentration of chloroquine enhanced efficacy of cisplatin in the treatment of human ovarian cancer dependent on autophagy. Am J Transl Res. 2017;9:4046-58 https://www. ncbi.nlm.nih.gov/pubmed/28979680.

34. Konecny GE, Glas R, Dering J, Manivong K, Qi J, Finn RS, et al. Activity of the multikinase inhibitor dasatinib against ovarian cancer cells. Br J Cancer 2009; 101:1699. https://doi.org/10.1038/sj.bjc.6605381.

35. Maione P, Gridelli C, Troiani T, Ciardiello F. Combining targeted therapies and drugs with multiple targets in the treatment of NSCLC. Oncologist. 2006;11:274-84.

36. Madhusudan S, Muthuramalingam SR, Braybrooke JP, Wilner S, Kaur K, Han $C$, et al. Study of Etanercept, a tumor necrosis factor-alpha inhibitor, in recurrent ovarian Cancer. J Clin Oncol. 2005;23:5950-9. https://doi.org/10. 1200/JCO.2005.04.127.

37. Takatori E, Shoji T, Miura Y, Takada A, Takeuchi S, Sugiyama T. Effective use of everolimus as salvage chemotherapy for ovarian clear cell carcinoma: a case report. Onco Targets Ther. 2014;7:165-9. https://doi.org/10.2147/OTT. S54745.

38. Ohta T, Ohmichi M, Shibuya T, Takahashi T, Tsutsumi S, Takahashi K, et al. Gefitinib (ZD1839) increases the efficacy of cisplatin in ovarian cancer cells. Cancer Biol Ther. 2012:13:408-16. https://doi.org/10.4161/cbt.19292.

39. Matei D, Chang DD, Jeng M-H. Imatinib mesylate (gleevec) inhibits ovarian cancer cell growth through a mechanism dependent on platelet-derived growth factor receptor $a$ and akt inactivation. Clin Cancer Res. 2004;10:681 LP-690. https://doi.org/10.1158/1078-0432.CCR-0754-03.

40. Charles KA, Hoare SA, Hagemann T, Scott D, Aird R, Smyth J, et al. Infliximab, a humanised anti-TNF-a monoclonal antibody, exhibits biological activity in the ovarian tumor microenvironment in patients. Cancer Res. 2006;66(8 Supplement):1055 LP-1056 http://cancerres.aacrjournals.org/ content/66/8_Supplement/1055.4.abstract. 
41. Hall M, Gourley C, McNeish I, Ledermann J, Gore M, Jayson G, et al. Targeted anti-vascular therapies for ovarian cancer: current evidence. $\mathrm{Br} J$ Cancer. 2013;108:250-8. https://doi.org/10.1038/bjc.2012.541.

42. Jiang Y, Gou H, Zhu J, Tian S, Yu L. Lidocaine inhibits the invasion and migration of TRPV6-expressing cancer cells by TRPV6 downregulation. Oncol Lett. 2016;12:1164-70. https://doi.org/10.3892/ol.2016.4709.

43. Novetsky AP, Thompson DM, Zighelboim I, Thaker PH, Powell MA, Mutch $D G$, et al. Lithium chloride and inhibition of glycogen synthase kinase $3 \beta$ as a potential therapy for serous ovarian cancer. Int J Gynecol Cancer. 2013;23: 361-6. https://doi.org/10.1097/IGC.0b013e31827cfecb.

44. Steward WP. Marimastat (BB2516): Current status of development. 1999.

45. Pourgholami MH, Ataie-Kachoie P, Badar S, Morris DL. Minocycline inhibits malignant ascites of ovarian cancer through targeting multiple signaling pathways. Gynecol Oncol 2013;129:113-119. doi:https://doi.org/10.1016/j. ygyno.2012.12.031

46. Siwak DR, Carey M, Hennessy BT, Nguyen CT, McGahren Murray MJ, Nolden $L$, et al. Targeting the epidermal growth factor receptor in epithelial ovarian cancer: current knowledge and future challenges. J Oncol. 2010;2010: 568938. https://doi.org/10.1155/2010/568938.

47. du Bois A, Floquet A, Kim J-W, Rau J, del Campo JM, Friedlander M, et al. Incorporation of Pazopanib in maintenance therapy of ovarian Cancer. J Clin Oncol. 2014;32:3374-82. https://doi.org/10.1200/JCO.2014.55.7348.

48. Kaye SB, Vergote I, Poole CJ, Dańska-Bidzińska A, Gianni L, Del Conte G, et al. A randomized phase $\|$ study evaluating the combination of carboplatin-based chemotherapy with pertuzumab versus carboplatin-based therapy alone in patients with relapsed, platinum-sensitive ovarian cancer. Ann Oncol. 2012;24:145-52. https://doi.org/10.1093/annonc/mds282.

49. Yin Z, Xu J, Zhou B, Wu D, Xu Y, Zhang J, et al. Topical pimecrolimus inhibits high-dose UVB irradiation-induced epidermal Langerhans cell migration, via regulation of TNF- $\alpha$ and E-cadherin. Drug Des Devel Ther. 2014:8:1817-25. https://doi.org/10.2147/DDDT.S70790.

50. Lang JD, Hendricks WPD, Orlando KA, Yin H, Kiefer J, Ramos P, et al. Ponatinib shows potent antitumor activity in small cell carcinoma of the ovary hypercalcemic type (SCCOHT) through multikinase inhibition. Clin Cancer Res. 2018;24:1932 LP-1943. https://doi.org/10.1158/1078-0432.CCR17-1928.

51. Lim E, Chan J, Soh LT, Chan S, Tan T, Chay WY, et al. 301PInterim analysis of a single-arm phase 2 clinical trial of regorafenib in patients with epithelial ovarian cancer. Ann Oncol. 2017;28(suppl_10). https://doi.org/10.1093/ annonc/mdx663.013.

52. Schlosshauer PW, Li W, Lin K-T, Chan JL-K, Wang L-H. Rapamycin by itself and additively in combination with carboplatin inhibits the growth of ovarian cancer cells. Gynecol Oncol. 2009;114:516-22. https://doi.org/10. 1016/j.ygyno.2009.06.002

53. Matei D, Sill MW, Lankes HA, DeGeest K, Bristow RE, Mutch D, et al. Activity of sorafenib in recurrent ovarian cancer and primary peritoneal carcinomatosis: a gynecologic oncology group trial. J Clin Oncol. 2011;29: 69-75. https://doi.org/10.1200/JCO.2009.26.7856.

54. Veera Subhashini G, Latha BS. Sulfasalazine inhibits IL-2 expression in ovarian Cancer cells; 2017.

55. Kim J-S, Baek SJ, Sali T, Eling TE. The conventional nonsteroidal antiinflammatory drug sulindac sulfide arrests ovarian cancer cell growth via the expression of \&lt;em\&gt;NAG-1/MIC-1/GDF-15\&lt;/em\&gt. Mol Cancer Ther. 2005;4:487 LP-493. https://doi.org/10.1158/1535-7163.MCT-04-0201.

56. DeVorkin L, Hattersley M, Kim P, Ries J, Spowart J, Anglesio MS, et al. Autophagy inhibition enhances Sunitinib efficacy in clear cell ovarian carcinoma. Mol Cancer Res. 2017;15:250-8. https://doi.org/10.1158/15417786.MCR-16-0132.

57. Yang $L$, Jackson E, Woerner BM, Perry A, Piwnica-Worms D, Rubin JB. Blocking CXCR4-mediated cyclic AMP suppression inhibits brain tumor growth in vivo. Cancer Res. 2007;67:651-8.

58. Emons G, Kurzeder C, Schmalfeldt B, Neuser P, de Gregorio N, Pfisterer J, et al. Temsirolimus in women with platinum-refractory/resistant ovarian cancer or advanced/recurrent endometrial carcinoma. A phase II study of the AGO-study group (AGO-GYN8). Gynecol Oncol 2016;140:450-456. doi: https://doi.org/10.1016/j.ygyno.2015.12.025.

59. Tempfer CB, Schultheis B, Hilal Z, Dogan A, Rezniczek GA. Thalidomide and lenalidomide for recurrent ovarian cancer: a systematic review of the literature. Oncol Lett. 2017;14:3327-36. https://doi.org/10.3892/ol.2017.6578.

60. Pétigny-Lechartier C, Duboc C, Jebahi A, Louis M-H, Abeilard E, Denoyelle C, et al. The mTORC1/2 Inhibitor AZD8055 strengthens the efficiency of the
MEK inhibitor trametinib to reduce the $\mathrm{mcl}-1 /[$ bim and puma] ratio and to sensitize ovarian carcinoma cells to ABT-737. Mol Cancer Ther. 2017;16:102 LP-115. https://doi.org/10.1158/1535-7163.MCT-16-0342.

61. Wilken JA, Webster KT, Maihle NJ. Trastuzumab sensitizes ovarian Cancer cells to EGFR-targeted therapeutics. J Ovarian Res. 2010;3:7. https://doi.org/ 10.1186/1757-2215-3-7.

62. Menderes G, Bonazzoli E, Bellone S, Altwerger G, Black JD, Dugan K, et al. Superior in vitro and in vivo activity of trastuzumab-emtansine (T-DM1) in comparison to trastuzumab, pertuzumab and their combination in epithelial ovarian carcinoma with high HER2/neu expression. Gynecol Oncol. 2017; 147:145-52. https://doi.org/10.1016/j.ygyno.2017.07.009.

63. ARZUMAN L, BEALE P, CHAN C, YU JUNQ, HUQ F. Synergism from combinations of tris(benzimidazole) monochloroplatinum(II) chloride with capsaicin, Quercetin, Curcumin and Cisplatin in human ovarian Cancer cell lines. Anticancer Res . 2014;34:5453-5464. http://ar.iiarjournals.org/ content/34/10/5453.abstract.

64. Annunziata CM, Walker AJ, Minasian L, Yu M, Kotz H, Wood BJ, et al. Vandetanib, designed to inhibit VEGFR2 and EGFR signaling, had no clinical activity as monotherapy for recurrent ovarian cancer and no detectable modulation of VEGFR2. Clin Cancer Res. 2010;16:664-72. https://doi.org/10. 1158/1078-0432.CCR-09-2308.

65. Carr AC, Vissers MCM, Cook JS. The effect of intravenous vitamin C on cancer- and chemotherapy-related fatigue and quality of life. Front Oncol. 2014;4:283. https://doi.org/10.3389/fonc.2014.00283.

66. Li F. Computational approaches and pharmacogenomics data resources for drug repositioning. Med Res Arch. 2017;5.

67. Xu J, Li F. A signaling network based computational model to uncover loop as the novel molecular mechanisms for medulloblastoma. bioRxiv. 2019;: https://doi.org/10.1101/561076.

68. Li F, Wang L, Kong R, Sheng J, Cao H, Mancuso J, et al. DrugMoaMiner: A computational tool for mechanism of action discovery and personalized drug sensitivity prediction. In: 3rd IEEE EMBS International Conference on Biomedical and Health Informatics: BHI 2016. pp. 368-371, https://doi.org/10. 1109/BHI.2016.7455911.

69. Zhang T, Zhang L, Payne P, Li F. Synergistic drug combination prediction by integrating multi-omics data in deep learning models. arXiv Prepr arXiv181107054. 2018.

70. Sheng J, Li F, Wong STC. Optimal drug prediction from personal genomics profiles. IEEE J Biomed Heal Informatics. 2015;19.

\section{Publisher's Note}

Springer Nature remains neutral with regard to jurisdictional claims in published maps and institutional affiliations.
Ready to submit your research? Choose BMC and benefit from:
- fast, convenient online submission
- thorough peer review by experienced researchers in your field
- rapid publication on acceptance
- support for research data, including large and complex data types
- gold Open Access which fosters wider collaboration and increased citations
- maximum visibility for your research: over $100 \mathrm{M}$ website views per year
At BMC, research is always in progress.
Learn more biomedcentral.com/submissions 